\title{
FAKTOR YANG BERHUBUNGAN DENGAN GANGGUAN KESEHATAN PADA PETANI BAWANG MERAH (AlliumCepa) DI DESA SARURAN KECAMATAN ANGGERAJA KABUPATEN ENREKANG
}

\author{
Sabaria ${ }^{1}$ dan Hidayat $^{2}$ \\ 1,2Jurusan Kesehatan Lingkungan Pltekkes Kemenkes Makassar \\ Email sabariahalim63@gmai.com
}

\begin{abstract}
Farmers are using pesticides to eliminate pests and weeds in the hope that agricultural products will increase. Organophosphate pesticides can be affecting neural function by blocking the cholinesterase enzyme in action, an essential chemical in delivering the impulses along the fibers Nerves. The goal of this study is to find a contributing factor in onion farmers (Allium cepa) in the village Saruran town of enrekang country. This type of research is observational analytic using the sectional cross method study Where the variables are free and bound are scrutinized simultaneously with samples of 87 respondents. The studies from the age group are linked to a medical institution where $p=0,000 \geq a=0.05$, earliest use of any connection at $p=0,000 \leq a=0,05$, the use of apd is associated with a medical disorder where $p=0,000$ rated $a=0.05$ levels are associated with a medical disorder where $p=0,000 \leq$ $a=0,05$, Spraying is related to a medical disorder that $p=0,000$ levels $=0.05$. The conclusion in this study is that there is a link between age, length of use, apd (self-contained tools), ways of cutting, and spraying Of treating leeks (Allium cepa) as a health hazard.

Keywords: onion farmer (Allium cepa), pesticide, health problems
\end{abstract}

\section{ABSTRAK}

Petani menggunakan pestisida untuk membasmi hama dan gulma dengan harapan hasil produk pertanian semakin meningkat. Pestisida organofosfat dapat mempengaruhi fungsi syaraf dengan jalan menghambat kerja enzim kholinestrase, suatu bahan kimia esensial dalam menghantarkan impuls sepanjang serabut syaraf. Tujuan dari penelitian ini untuk mengetahui faktor yang berhubungan dengan gangguan kesehatan pada petani bawang merah (Allium Cepa) di Desa Saruran Kecamatan Anggeraja Kabupaten Enrekang. Jenis penelitian ini adalah observasional analitik dengan menggunakan metode cross secstional study, dimana variable bebas dan terikat diteliti secara bersamaan dengan sampel sebanyak 87 responden. Hasil penelitian dari kelompok umur ada hubungan dengan gangguan kesehatan dimana $p=0,000 \geq a=0,05$, lama penggunaan ada hubungan dimana $p=0,000 \leq$ $a=0,05$, penggunaan APD ada hubungan dengan gangguan kesehatan dimana $p=0,000 \leq a=0,05$ cara peracikan ada hubungan dengan gangguan kesehatan dimana $p=0,000 \leq a=0,05$, cara penyemprotan ada hubungan dengan gangguan kesehatan dimana $p=0,000 \leq a=0,05$. Kesimpulan dalam penelitian ini yaitu ada hubungan antara umur, lama penggunaan, APD (alat pelingdung diri), cara peracikan, dan cara penyemprotan terhadap gangguan kesehatan pada petani bawang merah (Allium Cepa).

Kata Kunci : Petani Bawang (Allium Cepa), Pestisida, Gangguan Kesehatan

\section{Pendahuluan}

Pestisida merupakan subtansi kimia yang mempunyai daya bunuh yang tinggi, penggunaanya mudah, dan hasilnya cepat diketahui untuk membunuh atau mengendalikan berbagai hama tanaman. Tetapi pestisida ibarat tombak bermata dua. Di satu sisi pestisida mampu meningkatkan kesejahteraan masyarakat dengan meningkatkan hasil produksi petani. Tetapi di sisi lain pestisida adalah racun yang merusak manusia dan lingkungan apabila tidak tepat dalam menggunakannya.

Faktor yang berhubungan dengan kejadian keracunan pestisida organofosfat antara lain umur, jenis kelamin, pengetahuan, pengalaman, keterampilan, pendidikan, pemakaian alat pelindung diri, status gizi dan praktek penanganan pestisida. Sedangkan fase kritis yang harus diperhatikan adalah penyimpanan pestisida, percampuran pestisida, penggunaan pestisida dan pasca penggunaan pestisida.

Sifat pestisida yang dapat membunuh hama tanaman ini juga akan berdampak pada tubuh manusia, belum lagi jika jenis pestisida yang tidak mudah dinetralisir baik oleh alam maupun tubuh manusia tentunya akan memberi dampak baik yang sifatnya akut maupun kronis.

Dampak negatif yang ditimbulkan terhadap kesehatan manusia jika pestisida masuk kedalam tubuh baik melalui saluran pernafasan, kulit (yang paling sering) atau melalui saluran pencernaan dari konsumsi hasil pertanian yang mengandung residu pestisida.

Penggunaan pestisida tertinggi adalah pada lahan holtikultura dan diikuti tanaman pangan. Frekuensi aplikasi pestisida bisa mencapai 3-5 kali dalam seminggu dengan menggunakan lebih dari dua jenis pestisida dan bahkan bisa mencapai tujuh jenis pestisida. (Zulfikar, 2017)

Data keracunan akibat pestisida terbaru pada tahun 2014 Data Dinas Kesehatan Kabupaten Banjarnegara Jawa Tengah, dari 217 petani hanya 15 petani yang tidak keracunan, sebanyak 5 orang mengalami keracunan berat, 120 orang keracunan sedang, dan 77 orang keracunan ringan. Data Sentra Keracunan Nasional (2015). Pada bulan Juli-September 2015 terdapat satu insiden keracunan akibat pestisida pertanian. Satu insiden tidak sengaja terjadi di 
Jurnal Sulolipu : Media Komunikasi Sivitas Akademika dan Masyarakat

Vol. 20 No.12020

e-issn : 2622-6960, p-issn : 0854-624X

Jawa Timur yang disebabkan karena penggunaan pestisida pertanian tidak tepat. Pestisida tersebut adalah racun serangga yang menyebabkan korban sebanyak 29 orang dengan rute paparan terhirup. Beberapa kasus yang pernah terjadi di kalangan petani khususnya di Indonesia tidak terjadi begitu saja. Namun keracunan pestisida terjadi karena beberapa faktor, diantaranya kebersihan badan petani dan cara penyemrotan yang dilakukan dalam mengaplikasikan pestisida. Sedangkan pada tahun 2016 satu insiden keracunan terjadi di Jawa Tengah akibat satu keluarga mengonsumsi makanan yang tercampur pestisida pertanian yang mengakibatkan sebanyak 4 korban dengan satu diantaranya meninggal dunia. (A Qisthi, 2016)

Dari hasil observasi di desa Saruran dengan jumlah $520 \mathrm{KK}$, dan jumlah 2.197 jiwa, warga yang bermata pencaharian sebagai petani bawang sebanyak $110 \mathrm{KK}$. Dari hasil observasi juga di dapatkan data keracunan tiga tahun terakhir dan jumlah keracunan pada tahun 2015 sebanyak 20 orang, 2016 sebanyak 21 orang dan 2017 sebanyak 25 orang dengan gejala-gejala keracunan seperti pusing, mual, dan iritasi kulit bahkan mengeluh pingsan. (Data Desa Saruran, 2018)

\section{Bahan dan Metode}

\section{Lokasi Penelitian:}

Lokasi penelitian dilakukan di Desa Saruran Kecamatan Anggeraja Kabupaten Enrekang.

\section{Waktu Penelitian}

Waktu penelitian ini dibagi dua tahap yaitu:

a. Tahapan persiapan, meliputi obeservasi untuk penyusunan penelitian dan pengumpulan data primer dan data sekunder yang di laksanakan pada bulan DesemberJanuari 2019.

b. Tahapan penelitian, penelitian yang dilakukan pada bulan Februari-Mei 2019.

\section{Desain dan Variabel Penelitian}

Jenis penelitian ini adalah penelitian observasional analitik dengan pendekatan Cross Sectional study yang bertujuan untuk mengetahui faktor yang berhubungan dengan gangguan kesehatan pada petani bawang merah (Allium Cepa) di desa Saruran Kecamatan Anggeraja Kabupaten Enrekang.

\section{Populasi dan Sampel}

\section{Populasi}

Populasi dalam penelitian ini adalah semua petani bawang merah (Allium Cepa) yang ada di desa

Saruran sebanyak $110 \mathrm{KK}$.

\section{Sampel}

Jadi sampel yang digunakan sebanyak 87 responden. Sampel yang di ambil menggunakan metode Simple Random Sampling (sistem acak).

\section{Pengumpulan data}

\section{Data Primer}

Data primer dalam penelitian ini diperoleh dari para responden dengan menggunakan kuesioner dan observasi di lapangan secara langsung. Data primer yang di kumpulkan dalam penelitian ini meliputi data tentang hubungan pestisida gangguan kesehatan pada petani bawang merah (Allium Cepa) di desa Saruran Kecamatan Anggeraja Kabupaten Enrekang.

\section{Data Sekunder}

Data sekunder adalah data yang diperoleh melalui penelusuran kepustakaan yang berhubungan dengan penelitian ini yaitu berupa buku referensi hasil penelitian, internet, dan perpustakaan Politeknik Kesehatan Makassar Jurusan Kesehatan Lingkungan.

\section{Analisa Data}

Analisis Univariat

Analisis Univariat dilakukan terhadap tiap variabel dari hasil penelitian dengan menggunakan tabel distribusi frekuensi sehingga menghasilkan distribusi dan persentase dari setiap variabel pada penelitian ini.

\section{Analisis Bivariat}

Analisa Bivariat ini adalah data yang di gunakan dalam penelitian ini yaitu menggunakan uji statistic dengan program SPSS berupa uji ChiSquare guna mengetahui hubungan dengan gangguan kesehatan pada petani bawang merah (Allium Cepa) di Desa Saruran Kecamatan Anggeraja Kabupaten Enrekang. 
Jurnal Sulolipu : Media Komunikasi Sivitas Akademika dan Masyarakat

Vol. 20 No.12020

e-issn : 2622-6960, p-issn : 0854-624X

Hasil

Tabel 1

Distribusi Responden Berdasarkan Kelompok Umur Di Desa Saruran Kec. Anggeraja Tahun 2019

\begin{tabular}{|c|c|c|c|}
\hline No & Kelompok umur & $\mathrm{N}$ & $\%$ \\
\hline 1. & $\begin{array}{l}\text { Dibawah } 35 \\
\text { tahun }\end{array}$ & 62 & $71 \%$ \\
\hline \multirow[t]{2}{*}{2.} & Diatas 35 tahun & 25 & $28 \%$ \\
\hline & Jumlah & 87 & $100 \%$ \\
\hline \multicolumn{4}{|c|}{$\begin{array}{c}\text { Tabel.2 } \\
\text { Distribusi Lama Penggunaan Pestisida di Desa } \\
\text { Saruran Kecamatan Anggeraja Kabupaten } \\
\text { EnrekangTahun } 2019\end{array}$} \\
\hline No & $\begin{array}{c}\text { Lama Penggunaan } \\
\text { Pestisida }\end{array}$ & $\mathrm{N}$ & $\%$ \\
\hline 1 & Memenuhi syarat & 65 & $75 \%$ \\
\hline 2 & $\begin{array}{l}\text { Tidak memenuhi } \\
\text { syarat }\end{array}$ & 22 & $25 \%$ \\
\hline & Total & 87 & $100 \%$ \\
\hline
\end{tabular}

Sumber Data Primer

Tabel 3

Distribusi Penggunaan Alat Pelindung Diri Petani di Desa Saruran Kecamatan Anggeraja Kabupaten EnrekangTahun 2019

\begin{tabular}{cccc}
\hline No & Penggunaan APD & $\mathrm{n}$ & $\%$ \\
\hline 1. & Memenuhi syarat & 49 & $56 \%$ \\
2. & $\begin{array}{l}\text { Tidak memenuhi } \\
\text { syarat }\end{array}$ & 38 & $44 \%$ \\
$\quad \begin{array}{l}\text { Jumlah } \\
\text { Sumber Data Primer }\end{array}$ & 87 & $100 \%$ \\
\hline
\end{tabular}

Tabel 4

Distribusi Peracikan Pestisida Petani di Desa Saruran Kecamatan Anggeraja Kabupaten EnrekangTahun 2019

\begin{tabular}{cccc}
\hline No & $\begin{array}{c}\text { Peracikan } \\
\text { pestisida }\end{array}$ & $\mathrm{n}$ & $\%$ \\
\hline 1 & Memenuhi syarat & 57 & $65 \%$ \\
2 & $\begin{array}{l}\text { Tidak memenuhi } \\
\text { syarat } \\
\quad \text { Total }\end{array}$ & 30 & $35 \%$ \\
\hline
\end{tabular}

Sumber Data Primer
Tabel 5

Distribusi Penyemprotan Pestisida Petani di Desa saruran Kecamatan Anggeraja Kabupaten Enrekang Tahun 2019

\begin{tabular}{cccc}
\hline No & $\begin{array}{c}\text { Penyemprotan } \\
\text { Pestisida }\end{array}$ & $\mathrm{n}$ & $\%$ \\
\hline 1 & Memenuhi syarat & 64 & $73 \%$ \\
2 & $\begin{array}{l}\text { Tidak memenuhi } \\
\text { syarat } \\
\text { Total }\end{array}$ & 23 & $26 \%$ \\
Sumber Data Primer & 87 & $100 \%$ \\
\hline
\end{tabular}

Tabel 6

Distribusi Gejala Keracunan Petani di Desa Saruran Kecamatan Anggeraja Kabupaten Enrekang Tahun 2019

\begin{tabular}{|c|c|c|c|c|}
\hline No & \multicolumn{2}{|c|}{ Gangguan kesehatan } & $\mathrm{n}$ & $\%$ \\
\hline 1 & $\begin{array}{l}\text { Ada } \\
\text { kesehatan }\end{array}$ & gangguan & 21 & $24 \%$ \\
\hline 2 & $\begin{array}{l}\text { Tidak ada } \\
\text { kesehatan }\end{array}$ & gangguan & 66 & $\begin{array}{l}76 \% \\
100 \%\end{array}$ \\
\hline
\end{tabular}

Sumber Data Primer

Tabel 7

Hubungan umur dengan gangguan kesehatan petani bawang merah di Desa Saruran tahun 2019

\begin{tabular}{|c|c|c|c|c|c|c|c|c|}
\hline \multirow{3}{*}{$\begin{array}{l}\mathrm{N} \\
\mathrm{O}\end{array}$} & \multirow{3}{*}{ Umur } & \multicolumn{6}{|c|}{ Gangguan kesehatan } & \multirow{3}{*}{$\begin{array}{c}\text { Statist } \\
\mathrm{ik}\end{array}$} \\
\hline & & \multicolumn{2}{|c|}{$\begin{array}{c}\text { Mengala } \\
\text { mi } \\
\text { Ganggu } \\
\text { an }\end{array}$} & \multicolumn{2}{|c|}{$\begin{array}{c}\text { Tidak } \\
\text { Mengala } \\
\text { mi } \\
\text { Ganggu } \\
\text { an }\end{array}$} & \multirow[b]{2}{*}{$\begin{array}{l}\text { Juml } \\
\text { ah }\end{array}$} & \multirow[b]{2}{*}{$\begin{array}{l}\text { Pers } \\
\text { en }\end{array}$} & \\
\hline & & $\mathrm{N}$ & $\%$ & $\mathrm{n}$ & $\%$ & & & \\
\hline 1 & $\begin{array}{l}\text { Memen } \\
\text { uhi } \\
\text { syarat }\end{array}$ & 8 & $\begin{array}{l}9,1 \\
9\end{array}$ & $\begin{array}{l}5 \\
4\end{array}$ & $\begin{array}{l}62 \\
06\end{array}$ & 62 & $\begin{array}{l}71.2 \\
6\end{array}$ & \multirow[t]{2}{*}{$\begin{array}{l}P=0,0 \\
00\end{array}$} \\
\hline 2 & $\begin{array}{l}\text { Tidak } \\
\text { memen } \\
\text { uhi } \\
\text { syarat }\end{array}$ & $\begin{array}{l}1 \\
3\end{array}$ & $\begin{array}{l}14, \\
98\end{array}$ & $2^{1}$ & $\begin{array}{l}13 \\
79\end{array}$ & 25 & $\begin{array}{l}28,7 \\
3\end{array}$ & \\
\hline & Jumlah & $\begin{array}{l}2 \\
1\end{array}$ & $\begin{array}{l}24, \\
17\end{array}$ & $\begin{array}{l}6 \\
6\end{array}$ & $\begin{array}{l}75 \\
85\end{array}$ & 87 & $\begin{array}{l}99,9 \\
9\end{array}$ & \\
\hline
\end{tabular}

Sumber Data Primer 
Jurnal Sulolipu : Media Komunikasi Sivitas Akademika dan Masyarakat

Vol. 20 No.12020

e-issn : 2622-6960, p-issn : 0854-624X

Tabel 8

Hubungan lama penggunaan pestisida dengan gangguan kesehatan pada petani bawang merah di Desa Saruran Tahun 2019

\begin{tabular}{|c|c|c|c|c|c|c|c|c|}
\hline \multirow{3}{*}{$\begin{array}{l}\mathrm{N} \\
\mathrm{O}\end{array}$} & \multirow{3}{*}{$\begin{array}{l}\text { Lama } \\
\text { penggun } \\
\text { aan } \\
\text { pestisida }\end{array}$} & \multicolumn{6}{|c|}{ Gangguan kesehatan } & \multirow{3}{*}{$\begin{array}{c}\text { Statis } \\
\text { tik }\end{array}$} \\
\hline & & \multicolumn{2}{|c|}{$\begin{array}{l}\text { Mengala } \\
\text { mi } \\
\text { Ganggu } \\
\text { an }\end{array}$} & \multicolumn{2}{|c|}{$\begin{array}{c}\text { Tidak } \\
\text { Mengala } \\
\text { mi } \\
\text { Ganggu } \\
\text { an }\end{array}$} & & & \\
\hline & & $\mathrm{N}$ & $\%$ & $\mathrm{~N}$ & $\%$ & $\begin{array}{c}\text { Juml } \\
\text { ah }\end{array}$ & $\begin{array}{c}\text { Pers } \\
\text { en }\end{array}$ & \\
\hline 1 & $\begin{array}{l}\text { Memenu } \\
\text { hi Syarat }\end{array}$ & 0 & 0 & $\begin{array}{l}6 \\
5\end{array}$ & $\begin{array}{l}74, \\
71\end{array}$ & 65 & $\begin{array}{c}74,7 \\
1\end{array}$ & $\begin{array}{l}P=0,0 \\
00\end{array}$ \\
\hline 2 & $\begin{array}{l}\text { Tidak } \\
\text { Memenu } \\
\text { hi Syarat }\end{array}$ & $\begin{array}{l}2 \\
1\end{array}$ & $\begin{array}{l}24 \\
13\end{array}$ & 1 & $\begin{array}{l}1,1 \\
4\end{array}$ & 22 & $\begin{array}{c}25,2 \\
8\end{array}$ & \\
\hline & Jumlah & $\begin{array}{l}2 \\
1 \\
\end{array}$ & $\begin{array}{l}24 \\
13\end{array}$ & $\begin{array}{l}6 \\
6 \\
\end{array}$ & $\begin{array}{l}75 \\
85\end{array}$ & 87 & $\begin{array}{c}99,9 \\
9\end{array}$ & \\
\hline
\end{tabular}

Sumber Data Primer

Secara statistic hasil data menggunakan uji chi-square diperoleh nilai $\mathrm{P}=0,000 \quad(\mathrm{p}<0,05)$, ini berarti $\mathrm{Ha}$ diterima dan $\mathrm{H}_{0}$ ditolak, maka dapat disimpulkan bahwa lama penggunaan pestisida berhubungan dengan gangguan kesehatan pada petani bawang merah (Allium Cepa) di Desa Saruran Kecamatan Anggeraja Kabupaten Enrekang tahun 2019.

Tabel 9

Hubungan penggunaan APD (Alat pelindung diri) dengan gangguan kesehatan petani bawang di Desa Saruran Tahun 2019

\begin{tabular}{|c|c|c|c|c|c|c|c|c|}
\hline \multirow{3}{*}{$\begin{array}{l}\mathrm{N} \\
\mathrm{O}\end{array}$} & \multirow{3}{*}{$\begin{array}{l}\text { Penggun } \\
\text { aan APD }\end{array}$} & \multicolumn{6}{|c|}{ Gangguan kesehatan } & \multirow{3}{*}{$\begin{array}{c}\text { Statis } \\
\text { tik }\end{array}$} \\
\hline & & \multicolumn{2}{|c|}{$\begin{array}{l}\text { Mengala } \\
\text { mi } \\
\text { Ganggu } \\
\text { an }\end{array}$} & \multicolumn{2}{|c|}{$\begin{array}{c}\text { Tidak } \\
\text { Mengala } \\
\text { mi } \\
\text { Ganggua } \\
n\end{array}$} & & & \\
\hline & & $\mathrm{N}$ & $\%$ & $\mathrm{~N}$ & $\%$ & $\begin{array}{l}\text { Juml } \\
\text { ah }\end{array}$ & $\begin{array}{l}\text { Pers } \\
\text { en }\end{array}$ & \\
\hline 1 & $\begin{array}{l}\text { Memenu } \\
\text { hi Syarat }\end{array}$ & 1 & $\begin{array}{l}1,1 \\
4\end{array}$ & $\begin{array}{l}4 \\
8\end{array}$ & $\begin{array}{l}55 \\
17\end{array}$ & 49 & $\begin{array}{l}56,3 \\
2\end{array}$ & $P=0,0$ \\
\hline 2 & $\begin{array}{l}\text { Tidak } \\
\text { Memenu } \\
\text { hi Syarat }\end{array}$ & $\begin{array}{l}2 \\
0\end{array}$ & $\begin{array}{l}22 \\
98\end{array}$ & $8^{1}$ & $\begin{array}{l}20 \\
68\end{array}$ & 38 & $\begin{array}{l}43,6 \\
7\end{array}$ & \\
\hline & Jumlah & $\begin{array}{l}2 \\
1\end{array}$ & $\begin{array}{l}24 \\
12\end{array}$ & $\begin{array}{l}6 \\
6\end{array}$ & $\begin{array}{l}75 \\
85\end{array}$ & 87 & $\begin{array}{l}99,9 \\
9\end{array}$ & \\
\hline
\end{tabular}

Secara statistic hasil data menggunakan uji chi-square diperoleh nilai $P=0,000 \quad(p<0,05)$, ini berarti $\mathrm{Ha}$ diterima dan $\mathrm{H}_{0}$ ditolak, maka dapat disimpulkan bahwa Alat Pelindung Diri (APD) berhubungan dengan gangguan kesehatan pada petani bawang merah (Allium Cepa) di Desa Saruran Kecamatan Anggeraja Kabupaten Enrekang tahun 2019.

Tabel 10

Hubungan cara peracikan pestisida dengan gangguan kesehatan petani bawang di Desa Saruran Tahun 2019

Gangguan kesehatan

\begin{tabular}{cccc}
$N$ & Peraci & & \\
\cline { 3 - 4 } o & kan & Stat \\
pestisi & Mengal & Tidak & ami \\
da & $\begin{array}{c}\text { ami } \\
\text { Ganggu }\end{array}$ & $\begin{array}{c}\text { MengalamiGa } \\
\text { ngguan }\end{array}$ &
\end{tabular}

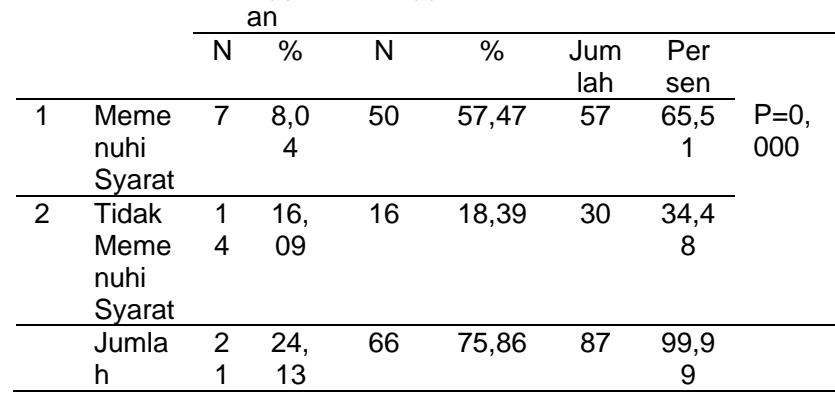

Sumber Data Primer

Secara statistic hasil data menggunakan uji chi-square diperoleh nilai $P=0,000 \quad(p<0,05)$, ini berarti $\mathrm{Ha}$ diterima dan $\mathrm{H}_{0}$ ditolak, maka dapat disimpulkan bahwa cara peracikan pestisida berhubungan dengan gangguan kesehatan pada petani bawang merah (Allium Cepa) di Desa Saruran Kecamatan Anggeraja Kabupaten Enrekang tahun 2019.

Tabel 11

Hubungan cara penyemprotan dengan gangguan kesehatan petani bawang di Desa Saruran Tahun 2019

\begin{tabular}{|c|c|c|c|c|c|c|c|c|}
\hline \multirow{3}{*}{$\begin{array}{l}\mathrm{N} \\
\mathrm{O}\end{array}$} & \multirow{3}{*}{$\begin{array}{l}\text { Cara } \\
\text { penyem } \\
\text { protan }\end{array}$} & \multicolumn{6}{|c|}{ Gangguan kesehatan } & \multirow[b]{2}{*}{$\begin{array}{l}\text { Stati } \\
\text { stik }\end{array}$} \\
\hline & & \multicolumn{2}{|c|}{$\begin{array}{l}\text { MengalamiG } \\
\text { angguan }\end{array}$} & \multicolumn{3}{|c|}{$\begin{array}{l}\text { Tidak } \\
\text { Mengal } \\
\text { ami } \\
\text { Gangg } \\
\text { uan }\end{array}$} & & \\
\hline & & $\mathrm{n}$ & $\%$ & $\mathrm{n}$ & $\%$ & $\begin{array}{l}\text { Jum } \\
\text { lah }\end{array}$ & $\begin{array}{l}\text { Per } \\
\text { sen }\end{array}$ & \\
\hline 1 & $\begin{array}{l}\text { Memen } \\
\text { uhi } \\
\text { Syarat }\end{array}$ & 9 & 10,34 & $\begin{array}{l}5 \\
5\end{array}$ & $\begin{array}{l}63 \\
21\end{array}$ & 64 & $\begin{array}{l}73 \\
56\end{array}$ & $\begin{array}{l}P=0 \\
000\end{array}$ \\
\hline 2 & $\begin{array}{l}\text { Tidak } \\
\text { Memen } \\
\text { uhi } \\
\text { Syarat }\end{array}$ & 12 & 13,79 & $\begin{array}{l}1 \\
1\end{array}$ & $\begin{array}{l}12 \\
64\end{array}$ & 23 & $\begin{array}{r}26 \\
43\end{array}$ & \\
\hline & Jumlah & 21 & 24,13 & $\begin{array}{l}6 \\
6\end{array}$ & $\begin{array}{l}75 \\
85\end{array}$ & 87 & $\begin{array}{c}99 \\
99\end{array}$ & \\
\hline
\end{tabular}

Sumber Data Primer 
Jurnal Sulolipu : Media Komunikasi Sivitas Akademika dan Masyarakat

Vol. 20 No.12020

e-issn : 2622-6960, p-issn : 0854-624X

Secara statistic hasil data menggunakan uji chi-square diperoleh nilai $P=0,000(p<0,05)$, ini berarti $\mathrm{Ha}$ diterima dan $\mathrm{H}_{0}$ ditolak, maka dapat disimpulkan bahwa cara peracikan pestisida berhubungan dengan gangguan kesehatan pada petani bawang merah (Allium Cepa) di Desa Saruran Kecamatan Anggeraja Kabupaten Enrekang tahun 2019.

\section{Pembahasan}

1. Hubungan Umur terhadap Gangguan Kesehatan Petani Bawang di Desa Saruran

Hubungan umur dengan gangguan kesehatan pada petani bawang merah (Allium Cepa), terhadap penggunaan pestisida di Desa Saruran di dapatkan hasil bahwa ada hubungan antara umur petani dengan gangguan kesehatan. Hal ini dapat dilihat dari hasil observasi di Desa Saruran Kecamatan Anggeraja Kabupaten Enrekang, bahwasannya berapapun umur petani namun kontak langsung dengan pestisida dengan tidak secara langsung (menggunakan APD) dan kurun waktu yang lama tidak menjadi penentu penyebab resiko petani mengalami gangguan kesehatan.

Berdasarkan pengamatan penulis dilapangan bahwa rata-rata umur petani yang tidak memenuhi syarat yaitu di atas 35 tahun masih aktif bekerja, dimana pada umur tersebut system imunitas/system kekebalan tubuh petani mulai menurun tetapi hal tersebut tidak mempengaruhi gangguan kesehatan terhadap penggunaan pestisida.

Sejalan dengan yang dikemukakan oleh Calista Paramitha, dkk, 2015 bahwa usia adalah fenomena alam, semakin lama seseorang hidup maka umurpun akan bertambah. Semakin bertambahnya umur seseorang semakin banyak yang dialaminya, dan semakin banyak pula pemaparan yang dialaminya,

dengan bertambahnya umur seseorang maka fungsi metabolisme akan menurun dan ini juga akan berakibat menurunnya aktifitas kholinesterase darahnya sehingga akan mempermudah terjadinya keracunan pestisida. Usia juga berkaitan dengan kekebalan tubuh dalam mengatasi tosksisitas suatu zat, semakin tua umur seseorang maka efektifitas sistem kekebalan di dalam akan semakin berkurang
2. Hubungan Lama Penggunaan Pestisida Terhadap Gangguan Kesehatan di Desa Saruran

Hubungan lama penggunaan pestisida dengan gangguan kesehatan pada petani bawang merah (Allium Cepa) di Desa Saruran Kecamatan Anggeraja Kabupaten Enrekang berdasarkan hasil observasi maka didapatkan hasil bahwa ada hubungan antara lama penggunaan pestisida dengan gangguan kesehatan petani bawang. Dimana pada saat dilakukan observasi di lapangan petani bawang yang telah menggunakan pestisida diatas 5 tahun yaitu sebanyak 22 orang (25\%). Dimana diketahui bahwa penggunaan pestisida diatas 5 tahun lebih rentan mengalami gangguan kesehatan. Seperti yang telah diketahui bahwa penggunaan pestisida secara langsung dalam jangka waktu yang lama dapat mengakibatkan keracunan seperti keracunan akut ringan, keracunan akut berat dan kronis.

Secara tidak sengaja pestisida dapat meracuni manusia melalui mulut, kulit, dan pernafasan. Sering tanpa disadari bahan kimia beracun tersebut masuk kedalam tubuh seseorang tanpa menimbulkan rasa sakit yang mendadak dan mengakibatkan keracunan kronis. Keracunan kronis akibat pestisida saat ini paling ditakuti karena efek racun dapat bersifat karsinogenik (pembentukan jaringan kanker pada tubuh), mutagenik (kerusakan genetic untuk generasi yang akan datang), dan danteratogenik (kelahiran anak cacat dari ibu yang keracunan pestisida).

Sebaiknya petani bawang lebih memperhatikan kesehatan apabila telah menggunakan pestisida diatas 5 tahun,dimana telah diketahui dampak dari kontak langsung dengan pestisida dalam jangka waktu yang lama atau diatas 5 tahun lebih beresiko mengalami gangguan kesehatan karena zat kimia yang terkandung didalam pestisida sangat beresiko dapat menyebabkan gangguan kesehatan seperti seperti keracunan akut ringan,keracunan akut berat dan kronis.

3. Hubungan Penggunaan APD (Alat Pelindung Diri) Terhadap Gangguan Kesehatan Petani Bawang di Desa Saruran Hubungan penggunaan APD (Alat Pelindung Diri) terhadap gangguan kesehatan pada petani bawang merah (Allium Cepa) 
Jurnal Sulolipu : Media Komunikasi Sivitas Akademika dan Masyarakat

Vol. 20 No.12020

e-issn : 2622-6960, p-issn : 0854-624X

berdasarkan hasil observasi di Desa Batunoni maka didapatkan bahwa ada hubungan antara penggunaan APD dengan gangguan kesehatan petani bawang merah (Allium Cepa) di Desa Saruran Kecamatan Anggeraja Kabupaten Enrekang, dimana pada saat observasi di lapangan masih ada 38 orang (44\%) petani yang tidak menggunakan APD pada saat melakukan kegiatan peracikan pestisida dan pada saat melakukan kegiatan penyemprotan pestisida. Dimana diketahui bahwa penggunaan APD (Alat Pelindung Diri) sangat penting digunakan pada saat kontak langsung dengan pestisida baik pada saat peracikan dan pada saat penyemprotan.

Penggunaan alat pelindung diri pada petani sangat penting untuk mencegah ganggguan kesehatan pada petani, karena pestisida dapat mengkontaminasi pengguna secara langsung sehingga dapat mengakibatkan keracunan, keracunan akibat

pestisida dapat masuk kedalam tubuh melalui mulut, kulit dan saluran pernapasan, sehingga penggunaan alat pelindung diri yang lengkap dan sesuai dengan Standar Operasional Profesional (SOP) dapat mencegah terjadinya gangguan kesehatan akibat pestisida.

Seperti yang dikemukakan yang dikemukakan oleh Eva F. Gudgin Dickson, 2012 bahwa alat pelindung diri merupakan alat yang dipakai untuk melindungi pemakainya dari beberapa bahaya eksternal, dalam hal ini kimia, biologi, radiologi, atau nuklir, yang semuanya dianggap beracun.

Keracunan akut ringan menimbulkan pusing, sakit kepala, iritasi ringan, badan terasa sakit, diare. Keracunan akut berat menimbulkan gejala mual, menggigil, kejang perut, sulit bernapas, keluar air liur, pupil mata mengecil, dan denyut nadi meningkat. Selanjutnya, keracunan yang sangat berat dapat mengakibatkan pingsan, kejang-kejang, bahkan bisa mengakibatkan kematian.

\section{Hubungan Cara Peracikan dengan Gangguan Kesehatan pada Petani Bawang di Desa Saruran}

Hubungan peracikan pestisida terhadap gangguan kesehatan petani bawang berdasarkan hasil observasi maka didapatkan hasil bahwa ada hubungan antara cara peracikan dengan gangguan kesehatan petani bawang. Dimana pada saat dilakukan observasi dilapangan masih ada 30 orang
(35\%) petani bawang yang tidak memenuhi syarat pada saat melakukan kegiatan peracikan pestisida. Seperti yang telah diketahui bahwa cara peracikan pestisida yang benar haruslah perhatikan karna peracikan yang tidak memenuhi syarat dapat menyebabkan gangguan kesehatan pada petani bawang.

Cara peracikan yang benar yaitu mencampur pestisida sesuai dengan takaran yang telah di anjurkan pada label kemasan, mengaduk campuran dengan hati-hati agar tidak tumpah,juga memperhatikan tempat pencampuran pestisida yaitu di tempat yang terbuka agar yang memiliki sirkulasi udara yang baik karena dapat mengakibatkan keracunan apabila di campur di tempat yang tertutup, atau di tempat yang sirkulasi udaranya kurang baik.

Sejalan dengan penelitian yang dilakukan oleh saudari Eka Lestari Mahyuni 2014 di Kabupaten Karo Kecamatan Berastagi bahwa ada hubungan antara cara peracikan dengan gangguan kesehatan petani bawang. Karena proses pencampuran pestisida yang kurang tepat yaitu di dalam ruangan yang tertutup untuk menghindari adanya hembusan angin yang dapat menyebabkan terbangnya pestisida dan mengenai tubuh petani. Dimana hal ini bertentangan dengan teori bahwa pencampuran pestisida sebaiknya dilakukan ditempat yang memiliki sirkulasi udara yang baik karena di tempat yang tertutup pestsida meiliki daya racun yang lebih tinggi sehingga dapat mengakibatkan keracunan melalui pernafasan.

\section{Hubungan Cara Penyemprotan Pestisida dengan Gangguan Kesehatan pada Petani Bawang di Desa Saruran}

Hubungan cara penyemprotan pestisida terhadap gangguan kesehatan pada petani bawang di Desa Saruran Kecamatan Anggeraja Kabupaten Enrekang di dapatkan hasil bahwa ada hubungan antara cara penyemprotan dengan gangguan kesehatan petani bawang merah (Allium Cepa). Dimana pada saat dilakukan observasi di lapangan masih ada $28(32 \%)$ petani bawang merah (Allium Cepa) yang tidak memenuhi syarat pada saat melakukan penyemprotan, seperti melakukan penyemprotan berlawanan 
Jurnal Sulolipu : Media Komunikasi Sivitas Akademika dan Masyarakat

Vol. 20 No.12020

e-issn : 2622-6960, p-issn : 0854-624X

dengan arah angin,hal ini sangat beresiko menyebabkan tejadinya gangguan kesehatan pada petani bawang.

Cara penyemprotan yang salah dapat menyebabkan gangguan kesehatan seperti petani yang melakukan penyemprotan yang salah arah, petani yang melakukan penyemprotan pada siang hari sehingga kondisi angin lebih cepat sehingga dapat menyebabkan petani dapat terpapar dengan pestisida karena arah angin yang dapat mengenai penyemprot sendiri.

Seperti yang dikemukakan Rini WUdianto (1988), waktu yang paling baik untuk penyemprotan adalah pada waktu terjadi aliran udara naik yaitu antara pukul 08.00 - 11.00 WITA atau sore hari pukul 15.00 - 18.00 WITA. Penyemprotan terlalu pagi atau terlalu sore akan mengakibatkan pestisida yang menempel pada bagian tanaman akan terlalu lama mengering dan mengakibatkan tanaman yang disemprot keracunan. Selain itu penyemprotan yang terlalu pagi biasanya daun masih berembun sehingga pestisida yang disemprotkan tidak bisa merata ke seluruh permukaan daun. Sedangkan penyemprotan yang dilakukan saat matahari terik akan mengakibatkan pestisida mudah menguap dan mengurai oleh sinar ultraviolet dan jangan melakukan penyemprotan di saat angin kencang karena banyak pestisida yang tidak mengena sasaran. Juga jangan menyemprot dengan melawan arah angin, karena cairan semprot bisa mengena orang yang menyemprot.

\section{Kesimpulan dan Saran Kesimpulan}

1. Ada hubungan antara Umur dengan Gangguan Kesehatan pada petani bawang merah (Allium Cepa) di desa Saruran Kecamatan Anggeraja Kabupaten Enrekang tahun 2019.

2. Ada hubungan antara Lama Pengguanaan Pestisida dengan Gangguan Kesehatan pada petani bawang merah (Allium Cepa) di desa Sarura Kecamatan Anggeraja Kabupaten Enrekang tahun 2019.
3. Ada hubungan antara Alat Pelindung Diri (APD) dengan Gangngguan Kesehatan pada petani bawang merah (Allium Cepa) di desa Saruran Kecamatan Anggeraja Kabupaten Enrekang tahun 2019.

4. Ada hubungan antara Cara Peracikan Pestisida dengan Gangguan Kesehatan pada petani bawang merah (Allium Cepa) di desa Saruran Kecamatan Anggeraja Kabupaten Enrekang tahun 2019.

5. Ada hubungan antara Cara Penyemprotan Pestisida dengan Gangguan Kesehatan pada petani bawang merah (Allium Cepa) di desa Saruran Kecamatan Anggerja Kabupaten Enrekang tahun 2019.

\section{Saran}

1. Sebaknya para petani agar lebih memperhatikan kesehatannya dikarenakan gangguan kesehatan sangat berbengaruh terhadap umur, semakin meningkat umur maka gangguan kesehatan semakin mudah terserang oleh petani.

2. Sebaiknya para petani bawang merah (Allium Cepa) dalam lama penggunaan pestisida lebih memperhatikan masa penggunaannya agar tidak terjadi gangguan kesehatan pada petani.

3. Para petani bawang merah (Allium Cepa) dalam alat pelindung diri (APD) sebaiknya memakai alat pelindung diri (APD) dalam penyemprotan agar tidak terjadi gangguan kesehatan pada petani.

4. Dalam proses peracikan pestisida seorang petani sebaiknya menggunakan masker dan sarung tangan (APD) agar petani tersebut yang meracik pestisida tidak mengalami gangguan kesehatan.

5. Dalam proses penyemprotan pestisida ada hubungan antara penyemprotan dengan gangguan kesehatan pada petani, maka dalam penelitian selanjutnya sebaiknya pemeriksaan tes darah di laboratorium pada petani bawang dilakukan agar panelitian ini dan penelitian selanjutnya lebih akurat dalam hasil terhadap gangguan kesehatan pada petani bawang merah (Allium Cepa).

\section{Daftar Pustaka}

Achmadi Fahmi Umar.2013. Dasar-dasar penyakit berbasis lingkungan. Depok: Rajagrafindo Persada. Agus Rosyid Budiawan.2013. Faktor Resiko Cholinesterase Rendah Pada Petani Bawang Merah (online) http://download.portalgaruda.org (diakses pada tanggal 20 Desember 2018). 
Jurnal Sulolipu : Media Komunikasi Sivitas Akademika dan Masyarakat

Vol. 20 No.12020

e-issn : 2622-6960, p-issn : 0854-624X

Ardi Endarto.2018. Bawang Merah Teknik Budaya dan Peluang Usahanya. Yogyakarta: Trans Idea Publising.

Anonim, 2014. Teknik Penyemprotan Pestisida.(Online) http://lepetani desasawo.com. (Diakses tanggal 16 Desember 2018)

Aqisthi Wahida Rusdita.2016. Data Keracunan Pestisida di Indonesia (online) http://eprints.ums.ac.id. (diakses pada tanggal 19 Desember 2018).

Djojosumarto, 2004. Jalur MasukPestisida Kedalam Tubuh. (Online). https://www.ejurnal.com/2014.(Diakses Pada tanggal 25 Januari 2019)

Djojosumarto Panut.2008. Teknik Aplikasi Pestisida Petani. Yogyakarta: Konsius (online) www.ejurnal.com/2014 (diakses pada tanggal 16 Desember 2018).

Djojosumarto Panut.2014. Teknik Penyemprotan Pestisida (online) www.e-jurnal.com/2014 (diakses pada tanggal 16 Desember 2018).

Eka Lestari Mahyuni. 2014. Hubungan Faktor Resiko Dalam Penggunaan Pestisida Pada Petani di Beastagi Kabupaten Karo. (online) https://media.neliti.com/2014 (diakses tanggal 7 Juni 2019) Jaelani.2007. Khasiat Bawang Merah. Yogyakarta: Kanisius.

Republik Indonesia.2013. Peraturan Menteri Pertanian Tentang "Pedoman Pengembangan Generasi Muda Pertania" (online) http://perundangan.pertania.go.id (diakses pada tanggal 17 Desember 2018).

Republik Indonesia.2012. Kemenkes RI Pedoman Penggunaan Pestisida (online) http://pppl.depkes.go.id (diakses pada tanggal 17 Desember 2018).

Republik Indonesia.2010. Peraturan Menteri Tenaga Kerja da Transmigrasi. No 8 Tentang "Alat Pelindung Diri" (online) http://www.goegle.com/amp/s/aswinsh.wordpress.com (diakses pada tanggal 20 Desember 2018).

Rini Wudianto.2008. Petunjuk Penggunaan Pestisida. Jakarta: Penebar Swadaya.

Rifqa Damayanti.2017. Faktor-Faktor yang Berhubungan Dengan Gangguan Kesehatan Pada Petani Bawang Terhadap Penggunaan Pestisida di Desa Batunoni Kecamatan Anggeraja Kabupaten Enrekang. Makassar: Jurusan Kesehatan Lingkungan (KTI tidak untuk di publikasikan).

Sumayyah Annida, 2018. Hubungan Antara Frekuensi Dan Lama Penyemprotan Dengan Keracunan Pestisida Pada Petani Di Desa Sri Katon Kecamatan AdiluwiH Kabupaten Pringsewu. (Online). http://digilib.unila.ac.id/31082/3. (Diakses pada tanggal 25 Januari 2019)

Zulfikar.2017. Tingkat Penggunaan Pestisida Pada Tanaman Bawang Merah di Kecamatan Anggeraja Kabupaten Enrekang (online) http://digilib.unhas.ac.id (diakses pada tanggal 26 Desember 2018). 